\title{
Kinetics activity of Yersinia Intermedia Against ZnO Nanoparticles Either Synergism Antibiotics by Double-Disc Synergy Test Method
}

\author{
Motahareh Fathi Azar Khavarani ${ }^{2}$, Mahla Najafi ${ }^{2}$, Zahra Shakibapour ${ }^{2}$, Davood Zaeifi 1* \\ ${ }^{1}$ Department of Biology, University of Tehran, Tehran, Iran \\ ${ }^{2}$ Institute of Microbial and Molecular Research Center of Viravigene, Tehran, Iran \\ ${ }^{*}$ Correspondig author: Davood Zaeifi, Department of Biology, University of Tehran, Tehran, Iran. Tel: +98-2161112723, Fax: +98-2166492992, \\ E-mail: d.zaeifi@ut.ac.ir
}

Received: March 16, 2015; Revised: July 11, 2015; Accepted: December 27, 2015

\begin{abstract}
Background: Bacterial resistance to the commonly used antibacterial agents is an increasing challenge in the medicine, and a major problem for the health care systems; the control of their spread is a constant challenge for the hospitals.

Objectives: In this study, we have investigated the antimicrobial activity of the Zinc Oxide nanoparticles against clinical sample; Yersinia intermedia bacteria.

Materials and Methods: Nanoparticle susceptibility constants and death kinetic were used to evaluate the antimicrobial characteristics of the Zinc Oxide $(\mathrm{ZnO})$ against the bacteria. Antimicrobial tests were performed with $10^{8} \mathrm{cfu} . \mathrm{mL}^{-1}$ at baseline. At first, Minimum Inhibitory Concentration (MIC) of $\mathrm{ZnO}$ was determined and then nanoparticle suspension at one and two times of the MIC was used for death kinetic and susceptibility constant assay at 0 to 360 min treatment time.

Results: $\mathrm{ZnO}$ nanoparticles with size ranging from 10 to $30 \mathrm{~nm}$ showed the highest susceptibility reaction against $Y$. intermedia $\left(\mathrm{Z}=39.06 \mathrm{~mL} \cdot \mu \mathrm{g}^{-1}\right)$. The process of $Y$. intermedia death in $\mathrm{ZnO}$ suspension was assumed to follow the first-order kinetics and the survival ratio of bacteria decreased with the increasing treatment time. An increased concentration of the nanoparticle was seen to enhance the bactericidal action of the nanoparticle. Then we performed the best ratio of the nanoparticles on semi-sensitive and resistance antibiotic for the bacteria. However, based on experimental results, synergy of $\mathrm{ZnO}$ nanoparticles and Oxacilin was determined and $Y$. intermedia showed a higher sensitivity compared to the $\mathrm{ZnO}$ nanoparticles alone.

Conclusions: The results of the present study illustrates that $\mathrm{ZnO}$ has a strong antimicrobial effect and could potentially be employed to aid the bacterial control. It could also improve- antibacterial effects in combination with the antibiotics.

Keywords: Kinetic activity of nanoparticles; Yersinia intermedia; $\mathrm{ZnO}$
\end{abstract}

\section{Background}

Aquatic environments have an important role in the spread of the diseases. Yersinia species have an immense ability to adapt to the aquatic environments as they need minimum requirements for life, therefore they can live for a long time in the cold waters; hence surface waters and sewage could be good habitats for spreading of the diseases: Yersiniosis (1). In addition, the bacteria belonging to the Yersinia intermedia species could be seen in different animal kingdom (e.g. fish, oyster, shrimp, spiel, and domestic animals), as well as foods (milk, cream, flesh), and sometimes in ill or even healthy individuals especially in their stool (2).

It does not seem that Yersinia intermedia to have intestinal pathogenic genes. As well, it is not clearly defined whether they are pathogenic for human, as they are usually non-pathogenic unless they become clinically consistent with the human body. Nevertheless, according to the report by Agbonlahor the species causes four kinds of acute diarrhea $(3,4)$.

The species Yersinia intermedia is a member of the genus Yersinia that was identified as a distinct species of the $Y$. enterocolitica. This distinction was done based on the acid production when microbe is exposed to D-melibiose, D-raffinose, $\alpha$-methyl-diglucose, L-rhamnose. Applying citrate distinguishes $Y$. intermedia from the other Yersinia species (5) and has introduced as a new species in 1980s by Brenner and colleagues. This species was found to belong to family of Entrobacteriaceae (2). They are Gram- negative, poly 
type bacilli that show bipolar staining. Also, they are oxidase negative and catalase positive.

$Y$. intermedia was defined as a new species distinct from $Y$. enterocolitica in 1980 based on DNA-DNA hybridizations and biochemical characteristics (6). The lipopolysaccharides of $Y$. intermedia is similar to those of $Y$. enterocolitica, and its carbohydrate utilization profile is similar to that of $Y$. enterocolitica as well as $Y$. pseudotuberculosis (6).

$Y$. intermedia has been mostly isolated from aquatic environments, such as freshwater, sewage, as well as invertebrate hosts such as fish, oysters, shrimps, snails, which are living in the aquatic environments. Association of the microbe with the mammals is evident as it could be isolated from milk, cream, and meat. It has also been reported that the bacterium could be isolated from the human urine, stool specimens, as well as from wound infections $(7,8)$, however it is rarely associated with the disease in human (9).

The bacteria are resistant to oxacillin, penicillin $\mathrm{G}$, amoxicillin, and are sensitive to cefotaxime, ceftazidime, chloramphenicol, ceftriaxone and sulfonamides. As well, they are sensitive to a lower extent to the nalidixic acid, ampicillin, and amikacin (1, 2, 10, $11)$. With regard to the tetracycline antibiotic, there were reports indicating diverse results through undertaking a set of different essays so far. In one case it was found that the bacteria are resistant, while in the other investigations it was found that they are susceptible to the Tetracycline $(2,11)$.

There is a large interest in the application of the inorganic antimicrobial agents as they have shown their advantages over the organic antimicrobial agents.

This interest, in part, is because of an improved safety and stability. Zinc oxide $(\mathrm{ZnO})$ is currently being investigated as an antimicrobial agent both in the microscale as well as nanoscale formulations. The obtained results so far have indicated that $\mathrm{ZnO}$ nanoparticles show an apparently superior antibacterial activity than $\mathrm{ZnO}$ microparticles $(12,13)$. The precise mechanism underlying the antibacterial action of the $\mathrm{ZnO}$ nanoparticles is not entirely well elucidated as yet. Different assumptions have so far been made, among which, the influence that reactive oxygen species (ROS) might have (14), the effect of the released Zinc ion, as well as the mechanical damage of the cell wall through adhesion to the cell membrane which might result and have an influence on the reaction system $\mathrm{pH}$ value. At higher concentration, small particles with a larger surface area ensure a more efficient antibacterial behavior, while, the crystalline structure, and particle shape probably have less influence (15).

Nowadays, researchers are trying to find a more pertinent method for treating this disease. Thus, nanomaterial that increasingly have received an expanded applications, have found their ways to our lives, and introduction of a new solution for treatment of the diseases. The various products of the nanotechnology have taken their applications in biology and medicine through many functions attributed to them. These materials are moving rapidly towards improving a new generation of medicines.

\section{Objectives}

The aim of the present study was to focus and find a solution for lifting drug resistance, in addition to using a lower dosage of the antibiotics for treating infections caused by the bacteria.

\section{Materials and Methods}

\subsection{Preparation of the Culture Medium}

$Y$. intermedia bacteria were obtained from positive culture of the clinical samples taken from patients with Yersiniosis and sent to Tehran University, Medical Sciences for culturing, using CIN Agar (CefsulodinIrgasan-Novobiocin, Merck, Germany) $(16,17)$.

\subsection{Sensitivity Test using the Kirby-Bauer Method}

In order to test the resistance of the $Y$. intermedia to the antibiotics, positive culture of the clinical samples of the $Y$. intermedia were cultured in Muller Hinton Agar medium (Merck, Germany), and Kirby Bauer disc diffusion method. The discs used in the present study were cefotaxime, tetracycline, nalidixic acid, oxacillin, amoxicillin, ampicillin, chloramphenicol, ceftazidime according to the following concentrations in micrograms: $30,30,30,30,30,10,25,10 \mu \mathrm{g}$ (Mast group Ltd. UK) respectively. The incubation was performed for $24 \mathrm{~h}$ at $3^{\circ} \mathrm{C}$ supplemented with $\% 5$ $\mathrm{CO}_{2}$ (semi-aerobic condition). After reading the zone of growth inhibition, a clinical specimen that was resistant to Oxacillin was used for further evaluation.

\subsection{Nanoparticle Suspensions Preparation}

$\mathrm{ZnO}$ nanoparticles (purity more than $99.7 \%$ ) with a size ranged from 10-30 nm was purchased from US NANO. To prepare a stock solution of nanoparticles, $10 \mathrm{~g}$ of the nanoparticles was turned into the suspension in one litter of the sterile medium. As well, for a proper dispensing of the particles, Electrosonic System 
(Bandelier Sonorex RK 31H) was used for $35 \mathrm{~min}$. In order to prevent errors, the preparation of the nanoparticle suspension and the microbial tests were performed simultaneously.

\subsection{Preparation of the Microbial Suspensions}

In order to prepare microbial suspension, first bacterial cells were picked from CIN agar medium by using a sterile loop and mixed in $10 \mathrm{~mL}$ of the sterile PBS (Buffered- phosphate) so that samples were prepared to a half McFarland turbidity (Colony Forming Unit (CFU) 1 to $1.5 \times 10^{8}$ ). The absorbance was measured by applying a UV/visble spectrophotometer (UNICO-2100, US) at $620 \mathrm{~nm}$ and absorption rate was adjusted in a range of 0.08-0.1 (18).

\subsection{Minimum Inhibitory Concentration (MIC) Test}

Using the standard method suggested by the national committee of the clinical laboratories standards (CLSI), MIC was calculated for the samples in contact with the nanoparticle suspension (16). MIC is defined as the minimum concentration of nanoparticles that prevent organisms' growth in the medium. Tubes containing the medium as batch systems were prepared with the different concentrations of the silver nanoparticle. In this method 12 tubes was used, each of which containing $2 \mathrm{~mL}$ of the sterile Triton Soya Broth (TSB) medium. In the first tube only $4 \mathrm{~mL}$ of the suspension was added and was mixed. Then $2 \mathrm{~mL}$ of this mixture was added to the second tube, and from this tube it was added to the next tube respectively. This process was done up to the $12^{\text {th }}$ tube (the resulting concentrations from the first to the twelfth tube declined accordingly from $10000,5000,2500,1250,625,312.5,156.25$, $78.125,39.06,19.53,9.765$ to a final of $4.883 \mu \mathrm{g} . \mathrm{mL}^{-1}$ ), respectively. Then the tubes containing nanoparticles and bacteria were incubated at $37^{\circ} \mathrm{C}$ for $24 \mathrm{~h}$ in a shaker incubator at a rate of shaking of $60 \mathrm{rpm}$.

\subsection{Bacterial Killing and Kinetics Activity}

The study of the bacterial kill-kinetics reveals the degree of the bacterial death and kinetics of which in contact with the nanoparticle suspension. The bacterial suspension was added to the medium in the tube containing nanoparticles with the MIC and then it was incubated in the shaker incubators ( $600 \mathrm{rpm}$, for maximum $24 \mathrm{~h}$ at $37^{\circ} \mathrm{C}$ ), considering the duration (from Zero to 360 $\mathrm{min}$ ). Samples were taken from the nanoparticle-bacterial suspension and were cultured on the plates containing Brain Heart Infusion (BHI) medium. The formed colonies at each time, bacteria and concentration were counted and were recorded. Survival rates $\left(\mathrm{N} / \mathrm{N}_{\circ}\right)$ was calculated through dividing the number of colonies at the time of the sampling $(\mathrm{N})$ by the number of colonies at the time when they had no contact with the silver nanoparticle suspension $\left(\mathrm{N}_{\circ}\right)$. In order to study the kill-kinetics of the bacteria, the first order kill-kinetics of the bacteria was used. The general formula for this kinetics is:

$\mathrm{dN} / \mathrm{dt}=-\mathrm{kN}$

In this equation $\mathrm{k}$ is the death rate constant, $\mathrm{N}_{\mathrm{o}}$, the number of initial bacterial colonies, $\mathrm{N}$, the number of bacterial colonies at the time $\mathrm{t}(19-21)$.

\subsection{Calculating Sensitivity Coefficients to the Nanoparticle Suspensions}

Here, the sensitivity coefficient of the nanoparticles is calculated through application of the following equation $\left(\mu \mathrm{g} \cdot \mathrm{mL}^{-1}\right)$, suggested by Yoon et al. (22).

$\mathrm{Z}=\frac{\operatorname{Ln}\left(N / N_{o}\right)}{c}$

\subsection{Preparation of the Nanoparticles Impregnated Discs}

Sterile blank discs were saturated with the desired concentration of the nanoparticle suspension and incubated at room temperature for $24 \mathrm{~h}$.

\subsection{DDST Susceptibility Test}

Candidate antibiotics to which the $Y$. intermedia were resistant i.e. Penicillin, Oxacillin and semi- sensitive, i.e. Amoxicillin and Ampicillin, were assessed for DDST. Also the sensitive antibiotic were studied to investigate whether $\mathrm{ZnO}$ resonate the inhibitory effect or not. Hinton Moular agar medium were prepared, and $10 \mu \mathrm{g}$ amikacin, $10 \mu \mathrm{g}$ penicillin, $30 \mu \mathrm{g}$ amoxicillin and $10 \mu \mathrm{g}$ ampicillin discs were placed at a distance of $10 \mathrm{~mm}$ from center to center. The culture mediums were incubated at $37^{\circ} \mathrm{C}$ for $18 \mathrm{~h}$, then zone of inhibition for each disc was recorded.

Table 1. Sensitivity of the $Y$. intermedia to the applied antibiotics

\begin{tabular}{lcc}
\hline Antibiotic & $\mathbf{m g}$ & Zone Diameter $(\mathbf{m m})$ \\
\hline Nalidixic acid & 30 & 35 \\
Tetracycline & 30 & 34 \\
Cefotaxime & 30 & 36 \\
Ceftazidime & 10 & 25 \\
Chloramphenicol & 25 & 25 \\
Ampicillin & 10 & 13 \\
Amoxycilin & 30 & 8 \\
Oxacilin & 30 & 0 \\
\hline
\end{tabular}




\section{Results}

\subsection{Kirby-Bauer Susceptibility Test}

(Table 1) summarizes the bacterial resistance to the antibiotics as were assessed through application of the impregnated discs in comparison to the standard samples.

\subsection{Preparation of the Nanoparticle Suspensions}

Figure 1A shows the X-ray powder diffraction (XRD) patterns of the commercial $\mathrm{ZnO}$ powder. There was not any diffraction pattern detection originating from impurity. Figure 1B shows the morphology and the corresponding particle size distributions over the volume of the prepared $\mathrm{ZnO}$ powders as were examined using TEM.

\subsection{Bacteria Killing and Kinetics Activity}

According to the results obtained through experiments for revealing antibacterial activity of the $\mathrm{ZnO}$ nanoparticle suspension against $Y$. intermedia, the MIC value for the bacteria in $\mathrm{ZnO}$ nanoparticles was found to be $39.06 \mu \mathrm{g} \cdot \mathrm{mL}^{-1}$.

The sensitivity coefficient of the $Y$. intermadia to the nanoparticle at different sampling periods was calculated. The result of such mean of sensitivity coefficient are shown in (Figure 2).

\subsection{DDST Susceptibility Test}

The results accumulated in the (Table 2) show significant DDST differences. It seems that there is a loss of sensitivity in synergy with the applied $\mathrm{ZnO}$ nanoparticles with Amoxcycilin and Ampicilin, as the zone became vanished, however, it also shows a higher sensitivity for Oxacilin due to visibility of the zone.

\section{Discussion}

The results obtained through application of the $\mathrm{ZnO}$ nanoparticle XRD, the purity of such nanoparticles were validated, as there is no impurity except oxygen. In addition, XRD images obtained for the nanoparticle show peaks which indicate the precise crystal structure of the nanoparticles $(23,24)$. The Transmission Electron Microscopy (TEM) pictures show the shape and size range of the nanoparticles. According to the image, $\mathrm{ZnO}$ nanoparticles' have relatively regular spherical shape, as well as, a size in the nanometer range. Reducing the nanoparticles size causes both structural and physico-chemical features to change, as a result, providing the organisms to have access for them, and, accordingly an increased toxic property (25). The reduction in the size, increase in the specific surface area, along with the rising of the reactive groups' number on nanoparticles surface have been already reported. The increase in the surface active groups may become as active sites for the formation of the reactive oxygen species (ROS) including superoxide, hydrogen peroxide, and hydrocele radical that lead to the oxidative stress. Regarding to (Figure 2 ), due to increased nanoparticles concentration, the inhibitory property of the nanoparticles against $Y$. intermadia have increased. Increasing nanoparticles concentration to achieve the MIC for that strain, it was observed a slight growth of the bacteria. In the other words, $\mathrm{ZnO}$ nanoparticles did not have the ability to kill the bacteria in the tested strain. However, results achieved in the present study have also indicated that for some synergies, an inhibitory effect could be observed as shown in (Tables 1 and 2).

Numerous studies regarding the antibacterial activity of the $\mathrm{ZnO}$ nanoparticles have been carried out,
$\mathbf{A}$

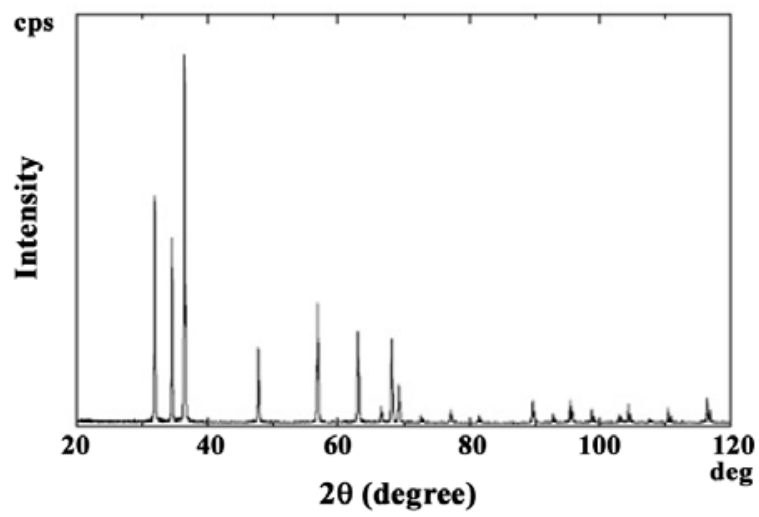

B

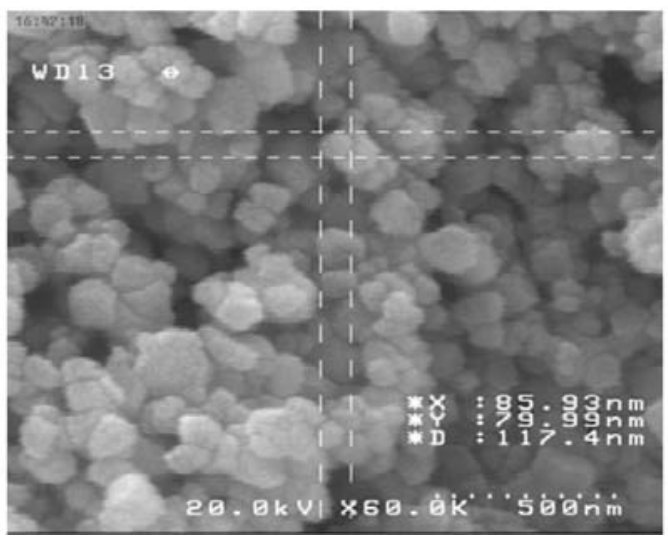

Figure 1. A: $\mathrm{XRD}$ of $\mathrm{ZnO}$ nanoparticles, $\mathrm{B}$ : TEM of the $\mathrm{ZnO}$ nanoparticles 


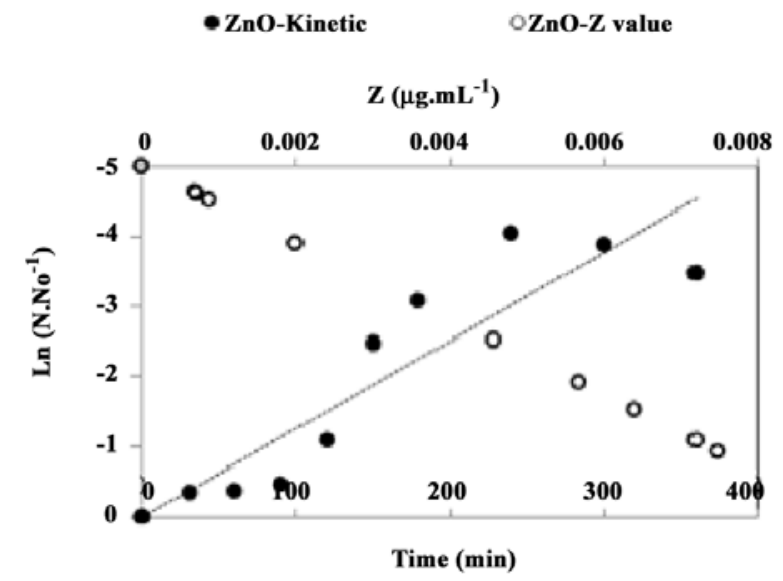

Figure 2. Coefficient sensitivity of $Y$. Intermedias population with respect to the time of investigation

however, most of which were focused on E. coli and $S$. aureus, and their synergy with a variety of antibiotics. M. Banoee et al. in 2009 have reported that the antibacterial activity of ciprofloxacin against the two clinical test strains: $S$. aureus and $E$. coli could be improved in the presence of $\mathrm{ZnO}$ nanoparticles (26). In another study, Reddy KM. et al. in 2007 have shown that the introduction of $\sim 13 \mathrm{~nm} \mathrm{ZnO}$ nanoparticle kills Gram-negative E. coli at concentration of $\geq 3.4 \mathrm{mM}$, whereas, growth of the Gram-positive $S$. aureus was prevented at much lower concentrations $(\geq 1 \mathrm{mM})$ (13). Seil et al. in 2012 have reported that the smalldiameter $\mathrm{ZnO}$ nanoparticles exhibit strong antibacterial properties against $S$. aureus that can also be additionally enhanced in the presence of ultrasound. Ahmad A. Tayel et al. (2011) have studied $\mathrm{ZnO}$ antibacterial activity on foodborne bacteria. Their results indicate that the exposure of Salmonella typhimurium and Staphylococcus aureus to their relevant minimal inhibitory concentrations of the $\mathrm{ZnO}$ nanoparticle

Table 2. Sensitivity of $Y$. intermedia in synergy with $\mathrm{ZnO}$ nanoparticles

\begin{tabular}{lcc}
\hline Antibiotic & $\mathbf{m g}$ & Zone Diameter $\mathbf{( m m})$ \\
\hline Nalidixic acid & 30 & 35 \\
Tetracycline & 30 & 34 \\
Cefotaxime & 30 & 36 \\
Ceftazidime & 10 & 25 \\
Chloramphenicol & 25 & 25 \\
Ampicillin & 10 & 0 \\
Amoxycilin & 30 & 0 \\
Oxacilin & 30 & 16 \\
\hline
\end{tabular}

reduced the cell number to zero within 8 and 4 h, respectively.

Researches have stated that the dominant nanoparticles surface charge is a function of the $\mathrm{pH}$ in the culture medium. In a case when $\mathrm{pH}$ of the culture medium is lower than nanoparticles' $\mathrm{pH}$, nanoparticles surface area will have positive charge. In addition, in a case when the nanoparticles' surface $\mathrm{pH}$ is higher than medium, nanoparticles surface area will have negative charge. Demetri (26) has theoretically calculated the $\mathrm{pH}$ of the many syntheses such as $\mathrm{ZnO}$ nanoparticles. According to his studies, $\mathrm{pH}$ of $\mathrm{ZnO}$ nanoparticles is 10 . The studies for determining $\mathrm{pH}$ of the bacteria indicate that $\mathrm{pH}$ range for growth of microorganisms is between 2 and 4 (27). Gram-negative bacteria have a layer of lipopolysaccharide outside of their cell wall, under this cell wall there is a thin layer $(7-8 \mathrm{~nm})$ of peptidoglycan. Lipopolysaccharides are not as hard as peptidoglycans, because, there is an equipotential relation between lipid and polysaccharide. Lipopolysaccharides have negative charge, so they are attracted by nanoparticles with positive charge. Then as stated above, it can be concluded that the bacterial surface charge reduces as a result of repulsive forces (27). Hence, in order to overcome this inhibiting force, there must be a higher concentration of the nanoparticles in the culture medium, and perhaps a reason for the less sensitivity of the bacteria in the lower concentrations might be due electrostatic repulsive force.

Additionally, investigators have also suggested that nanoparticles may specifically become bound to the cell membrane outer space, and likely, they penetrate into the cells at higher concentrations (28).

\section{Conclusions}

According to the results presented in this study it could be concluded that $\mathrm{ZnO}$ nanoparticles at different concentrations show a growth inhibitory effect on bacteria causing clinical infections, and at concentrations higher than MIC, can kill bacteria effectively.

$\mathrm{ZnO}$ nanoparticle suspensions has inhibiting effects on the bacterial activity kinetics. In addition to the inhibitory effects, such nanoparticles, along with antibiotics could be a right choice for treating the bacteria causing clinical infections. However, this issue demands further studies in order to obtain a conclusive understanding of the nanoparticle action.

\section{References}

1. Tzelepi E, Arvanitidou M, Mavroidi A, Tsakris A. Antibiotic susceptibilities of Yersinia enterocolitica and Y. intermedia 
isolates from aquatic environments. J Med Microbiol. 1999;48(2):157-160. DOI: 10.1099/00222615-48-2-157

2. Martin L, Leclercq A, Savin C, Carniel E. Characterization of atypical isolates of Yersinia intermedia and definition of two new biotypes. J Clin Microbiol. 2009;47(8):2377-2380. DOI:10.1128/JCM.02512-08

3. Agbonlahor DE. Characteristics of Yersinia intermedia-like bacteria isolated from patients with diarrhea in Nigeria. $J$ Clin Microbiol. 1986;23(5):891-896. DOI: 0095-1137/86/050891-06

4. Baker PM, Farmer JJ, $3^{\text {rd }}$. New bacteriophage typing system for Yersinia enterocolitica, Yersinia kristensenii, Yersinia frederiksenii, and Yersinia intermedia: correlation with serotyping, biotyping, and antibiotic susceptibility. J Clin Microbiol. 1982;15(3):491-502. DOI: 0095-1137/82/03049112

5. Punsalang A Jr, Edinger R, Nolte FS. Identification and characterization of Yersinia intermedia isolated from human feces. J Clin Microbiol. 1987;25(5):859-862. DOI: 0095-1137/87/ 050859-04

6. Brenner DJ, Bercovier H, Ursing J, Alonso JM, Steigerwalt AG, Fanning GR, et al. Yersinia intermedia: A new species of enterobacteriaceae composed of rhamnose-positive, melibiose-positive, raffinose-positive strains (formerly called Yersinia enterocolitica or Yersinia enterocolitica-like). Curr Microbiol. 1980;4(4): 207-212. DOI: 10.1007/bf02605858

7. Bottone EJ. Yersinia enterocolitica: a panoramic view of a charismatic microorganism. CRC Crit Rev Microbiol. 1977;5(2):211-241. DOI: 10.3109/10408417709102312

8. Farmer JJ, 3rd, Davis BR, Hickman-Brenner FW, McWhorter A, Huntley-Carter GP, Asbury MA, et al. Biochemical identification of new species and biogroups of Enterobacteriaceae isolated from clinical specimens. J Clin Microbiol. 1985;21(1):46-76. DOI:0095-1137/85/010046-31

9. Butler T, Islam M, Islam MR, Azad AK, Huq MI, Speelman $\mathrm{P}$, et al. Isolation of Yersinia enterocolitica and Y. intermedia from fatal cases of diarrhoeal illness in Bangladesh. Trans $R$ Soc Trop Med Hyg. 1984;78(4):449-450. DOI: 10.1016/00359203(84)90057-9

10. Ahmedy A, Vidon DJ, Delmas CL, Lett MC. Antimicrobial susceptibilities of food-isolated strains of Yersinia enterocolitica, Y. intermedia, Y. frederiksenii, and Y. kristensenii. Antimicrob Agents Chemother. 1985;28(2):351-353. DOI: 10.1128/aac.28.2.351

11. Stock I, Wiedemann B. Natural antimicrobial susceptibilities and biochemical profiles of Yersinia enterocolitica-like strains: Y. frederiksenii, $Y$. intermedia, Y. kristensenii and $Y$. rohdei. FEMS Immunol Med Microbiol. 2003;38(2):139-152. DOI: 10.1016/s0928-8244(03)00179-2

12. Nair S, Sasidharan A, Divya Rani VV, Menon D, Nair S, Manzoor K, et al. Role of size scale of $\mathrm{ZnO}$ nanoparticles and microparticles on toxicity toward bacteria and osteoblast cancer cells. J Mater Sci Mater Med. 2009;20 Suppl 1:S235-241. DOI:10.1007/s10856-008-3548-5

13. Reddy KM, Feris K, Bell J, Wingett DG, Hanley C, Punnoose A. Selective toxicity of zinc oxide nanoparticles to prokaryotic and eukaryotic systems. Appl Phys Lett. 2007;90 (213902): 2139021-2139023. DOI: 10.1063/1.2742324

14. Dutta RK, Nenavathu BP, Gangishetty MK, Reddy AV. Studies on antibacterial activity of $\mathrm{ZnO}$ nanoparticles by ROS induced lipid peroxidation. Colloids Surf B Biointerfaces. 2012;94(0):143-150. DOI: 10.1016/j.colsurfb.2012.01.046

15. Yamamoto $O$. Influence of particle size on the antibacterial activity of zinc oxide. Int J Inorg Mater. 2001;3(7):643-646. DOI: 10.1016/s1466-6049 (01)00197-0

16. Food U, Administration D. Division of Antiinfective and Ophthalmology Drug Products (HFD-520)-Microbiological data for antibacterial drug products-development, analysis, and presentation. FDA. 2005;27-34.

17. Barry AL, Craig WA, Nadler H, Reller LB, Sanders CC, Swenson JM. Methods for determining bactericidal activity of antimicrobial agents: approved guideline. National Committee for Clinical Laboratory Standards. 1999;19(18):8-12.

18. Ruparelia JP, Chatterjee AK, Duttagupta SP, Mukherji S. Strain specificity in antimicrobial activity of silver and copper nanoparticles. Acta biomaterialia. 2008;4(3):707-716. DOI: 10. 1016/j.actbio.2007.11.006

19. Ohira T, Yamamoto O, Iida Y, Nakagawa ZE. Antibacterial activity of $\mathrm{ZnO}$ powder with crystallographic orientation. $J$ Mater Sci Mater Med. 2008;19(3):1407-1412. DOI: 10.1007/ s10856-007-3246-8

20. Sawai J, Shiga H, Kojima H. Kinetic analysis of the bactericidal action of heated scallop-shell powder. Int $J$ Food Microbiol. 2001;71(2-3):211-218. DOI: 10.1016/S01681605(01)00619-5

21. Sawai J, Himizu K, Yamamoto O. Kinetics of bacterial death by heated dolomite powder slurry. Soil Biol Biochem. 2005;37(8):1484-1489. DOI: 10.1016/j.soilbio.2005.01.011

22. Yoon KY, Hoon Byeon J, Park JH, Hwang J. Susceptibility constants of Escherichia coli and Bacillus subtilis to silver and copper nanoparticles. Sci Total Environ. 2007;373(23):572-575. DOI: $10.1016 /$ j.scitotenv.2006.11.007

23. Blinova I, Ivask A, Heinlaan M, Mortimer M, Kahru A. Ecotoxicity of nanoparticles of $\mathrm{CuO}$ and $\mathrm{ZnO}$ in natural water. Environ Pollut. 2010;158(1):41-47. DOI: 10.1016/j.envpol. 2009.08.017

24. Ruparelia JP, Chatterjee AK, Duttagupta SP, Mukherji S. Strain specificity in antimicrobial activity of silver and copper nanoparticles. Acta Biomater. 2008;4(3):707-716. DOI: 10.1016/j.actbio.2007.11.006

25. Akhavan $\mathrm{O}$, Ghaderi E. $\mathrm{Cu}$ and $\mathrm{CuO}$ nanoparticles immobilized by silica thin films as antibacterial materials and photocatalysts. Surf Coat Technol. 2010;205(1):219-223. DOI: 10.1016/j.surfcoat.2010.06.036

26. Banoee M, Seif S, Nazari ZE, Jafari-Fesharaki P, Shahverdi HR, Moballegh A, et al. ZnO nanoparticles enhanced antibacterial activity of ciprofloxacin against Staphylococcus aureus and Escherichia coli. J Biomed Mater Res B Appl Biomater. 2010;93(2):557-561. DOI:10.1002/jbm.b.31615

27. Lytle DA, Rice EW, Johnson CH, Fox KR. Electrophoretic mobilities of E. coli O157: $\mathrm{H} 7$ and wild-type E. coli strains. Appl Environ Microbiol. 1999;65(7):3222-3225. DOI: 00992240/99

28. Tiwari DK, Behari J, Sen P. Time and dose-dependent antimicrobial potential of Ag nanoparticles synthesized by top-down approach. Curr Sci. 2008;95(5):647-655. 